\title{
Annexin A6 is highly abundant in monocytes of obese and type 2 diabetic individuals and is downregulated by adiponectin in vitro
}

\author{
Fabian Stögbauer ${ }^{1}$, Johanna Weigert', \\ Markus Neumeier ${ }^{1}$, Josef Wanninger ${ }^{\prime}$, \\ Daniela Sporrer ${ }^{1}$, Markus Weber ${ }^{1}$, \\ Andreas Schäffler', Carlos Enrich², \\ Peta Wood ${ }^{3}$, Thomas Grewal ${ }^{3}$, \\ Charalampos Aslanidis ${ }^{4}$ and Christa Buechler ${ }^{1,5}$ \\ 'Department of Internal Medicine I \\ Regensburg University Hospital \\ Regensburg, Germany \\ ${ }^{2}$ Departament de Biologia Cellular \\ Facultat de Medicina \\ Universitat de Barcelona, Spain \\ ${ }^{3}$ Faculty of Pharmacy \\ Department of Pharmaceutical Chemistry \\ University of Sydney \\ Sydney, Australia \\ ${ }^{4}$ Institute of Clinical Chemistry and Laboratory Medicine \\ Regensburg University Hospital \\ Regensburg, Germany \\ ${ }^{5}$ Corresponding author: Tel, 49-941-944-7147; \\ E-mail, christa.buechler@klinik.uni-regensburg.de \\ DOI 10.3858/emm.2009.41.7.055
}

Accepted 19 February 2009

Abbreviations: AMPK, AMP-activated protein kinase; PPAR $\alpha$, peroxisome proliferator-activated receptor $\alpha$

\begin{abstract}
Adiponectin stimulates cholesterol efflux in macrophages and low adiponectin may in part contribute to disturbed reverse cholesterol transport in type 2 diabetes. Monocytes express high levels of annexin A6 that could inhibit cholesterol efflux and it was investigated whether the atheroprotective effects of adiponectin are accompanied by changes in annexin A6 levels. Adiponectin reduces annexin A6 protein whereas mRNA levels are not affected. Adiponectin-mediated activation of peroxisome proliferator-activated receptor $\alpha$ (PPAR $\alpha)$ and AMP-activated protein kinase (AMPK) does not account for reduced annexin A6 expression. Further, fatty acids and lipopolysaccharide that are elevated in obesity do not influence annex-
\end{abstract}

in A6 protein levels. Annexin A6 in monocytes from overweight probands or type 2 diabetic patients is significantly elevated compared to monocytes of normal-weight controls. Monocytic annexin A6 positively correlates with body mass index and negatively with systemic adiponectin of the blood donors. Therefore, the current study demonstrates that adiponectin reduces annexin A6 in monocytes and thereby may enhance cholesterol efflux. In agreement with these in vitro finding an increase of monocytic annexin A6 in type 2 diabetes monocytes was observed.

Keywords: adiponectin; annexin A6; diabetes mellitus, Type 2; monocytes; obesity

\section{Introduction}

The initial step in reverse cholesterol transport involves the removal and transfer of excess cholesterol from peripheral cells onto cholesterol acceptors, such as HDL or apolipoprotein A-I (Cavelier et al., 2006). This is followed by the transport of cholesterol-enriched HDL to the liver for biliary excretion (Cavelier et al., 2006; Schmitz et al., 2008). Plasma levels of HDL or apolipoprotein A-I are inversely correlated with the risk of atherosclerosis (Cavelier et al., 2006). In patients with the metabolic syndrome or type 2 diabetes mellitus low systemic HDL levels contribute to the higher risk and incidence of atherosclerotic disease (Bonora, 2006; Feig et al., 2008). These findings correlate with a $30 \%$ reduction in cholesterol efflux of monocyte-derived macrophages from patients with type 2 diabetes, indicating that initial steps in cholesterol export in diabetic patients are impaired (Mauldin et al., 2008). The molecular events in lipid efflux from monocytes are not fully understood, but recent studies point at the ATP- binding cassette transporters $A B C A 1$ and $A B C G 1$ as the main surface proteins that mediate cholesterol efflux to apolipoprotein A-I or HDL, respectively (Bodzioch et al., 1999; Klucken et al., 2000; Cavelier et al., 2006). Lack of ABCA1 function in Tangier disease correlates with an increased risk of atherosclerotic disease (Bodzioch et al., 1999; Cavelier et al., 2006), suggesting that aberrant expression of ABCA1 and/or ABCG1 might also play a role in 
type 2 diabetes or the metabolic syndrome. Indeed, while ABCA1 expression in diabetic monocytes was similar to control cells, ABCG1 expression was significantly reduced (Zhou et al., 2008; Mauldin et al., 2008).

Adiponectin is an atheroprotective adipokine whose circulating levels are reduced in patients with type 2 diabetes and/or atherosclerosis (Arita et al., 1999). Some of its atheroprotective features appear to affect cholesterol homeostasis in peripheral cells, as adiponectin reduces lipid accumulation and, stimulates reverse cholesterol transport in macrophages (Tsubakio-Yamamoto et al., 2008; Tian et al., 2009). Most interestingly, adiponectin strongly induces ABCA1 expression in monocytes, indicating that higher ABCA1 levels are atheroprotective and contribute to enhance cholesterol removal from cells (Tsubakio-Yamamoto et al., 2008). In support of this hypothesis, lentiviral overexpression of adiponectin in macrophages reduces lipid accumulation and enhances cholesterol efflux to apolipoprotein A-I (Tian et al., 2009). In contrast, adiponectin-deficient mice show a significant reduction in ABCA1 and ABCG1 expression which correlates with a decreased cholesterol efflux to apolipoprotein $A-I$ and to a minor extend to HDL, respectively (Tsubakio-Yamamoto et al., 2008).

We have recently identified that elevated expression levels of annexin A6, a member of a family of $\mathrm{Ca}^{2+}$-dependent binding proteins, perturb the intracellular distribution of cholesterol, leading to strongly reduced cholesterol levels at the plasma membrane (Cubells et al., 2007). Consequently, cholesterol efflux to cyclodextrin and physiological cholesterol acceptors like HDL is reduced in annexin A6 overexpressing cells (Cubells et al., 2007). Given that significant amounts of annexin $A 6$ are found in monocytes and macrophages (Hoyal et al., 1996; Probst-Cousin et al., 2004) in the current study it was analysed whether annexin A6 levels are altered in monocytes isolated of patients with type 2 diabetes compared to controls. Furthermore the influence of recombinant adiponectin on annexin A6 abundance in monocytes was investigated. We
A

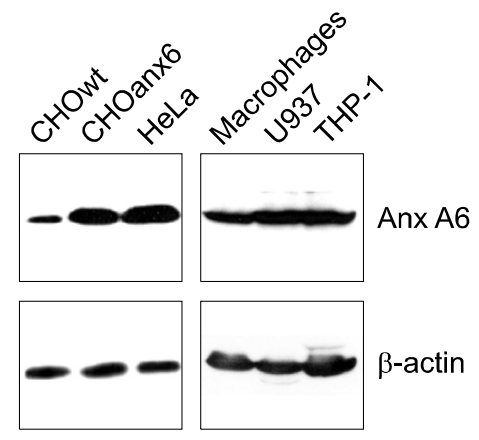

D
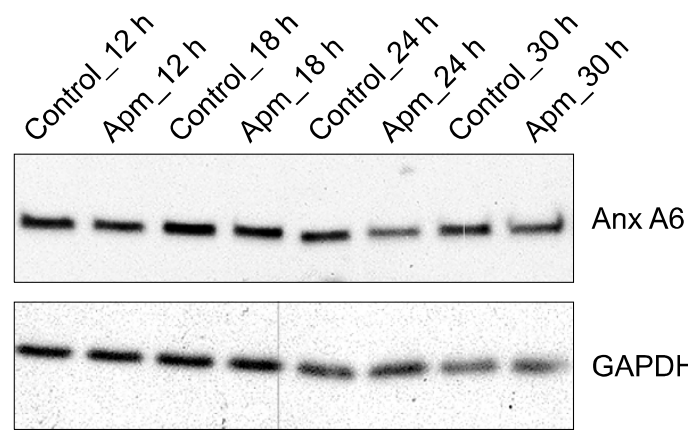

GAPDH

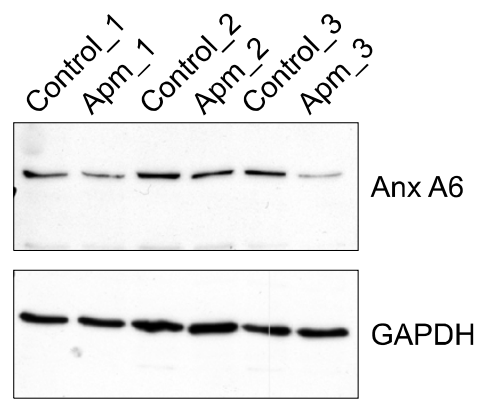

E

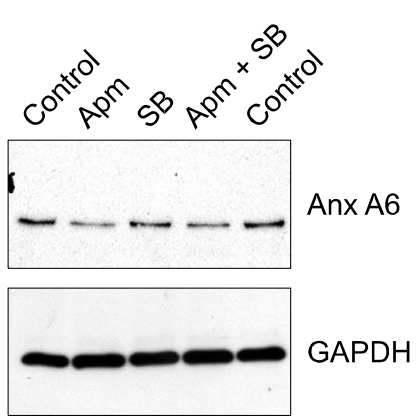

C

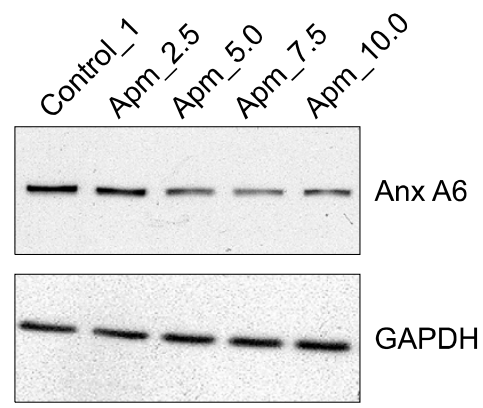

$\mathbf{F}$

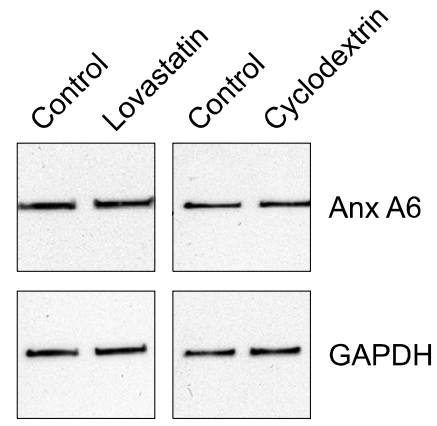

Figure 1. Adiponectin, but not cholesterol depletion, downregulates annexin $\mathrm{A} 6$ expression. (A) Annexin $\mathrm{A} 6$ protein levels in $\mathrm{CHO}$ wildtype (wt) cells, in $\mathrm{CHO}$ cells overexpressing annexin A6 (CHOanx6), in HeLa cells, in primary monocytes and the monocytic cell lines U937 and THP1. (B) Annexin A6 (Anx A6) and GAPDH in monocytes of 3 blood donors cultivated with or without $10 \mu \mathrm{g} / \mathrm{ml}$ adiponectin (Apm) for $24 \mathrm{~h}$. (C) Annexin A6 (Anx A6) and GAPDH in monocytes cultivated with 2.5, 5.0, 7.5 or $10.0 \mu \mathrm{g} / \mathrm{ml}$ adiponectin for $24 \mathrm{~h}$. (D) Annexin A6 and GAPDH in monocytes cultivated with $10 \mu \mathrm{g} / \mathrm{ml}$ adiponectin or without adiponectin for $12 \mathrm{~h}, 18 \mathrm{~h}, 24 \mathrm{~h}$ or $30 \mathrm{~h}$. (E) Annexin A6 in monocytes cultivated with adiponectin, the p38 MAPK inhibitor SB 203580 or both for $24 \mathrm{~h}$. (F) Annexin A6 in monocytes incubated with lovastatin or $\beta$-cyclodextrin for $16 \mathrm{~h}$. 
identified that annexin A6 levels are significantly elevated in monocytes from overweight probands or type 2 diabetic patients and that adiponectin reduces annexin $A 6$ protein in monocytes. The potential role of annexin $A 6$ as a downstream target of adiponectin to mediate its antiatheroprotective effects is discussed.

\section{Results}

Most cell types express annexin A6, and similar to HeLa cells and the previously described $\mathrm{CHOanx6}$ cell line (Cubells et al., 2008), blood-derived macrophages, the human monocytic cell lines U937 and THP1 express significant amounts of annexin A6 ( $\sim 3-5$ pg/cell; Figure 1A). Elevated annexin A6 levels disturb cellular cholesterol efflux (Cubells et al., 2007) and the effect of the atheroprotective adipokine adiponectin (Goldstein et al., 2004) on annexin A6 levels were analysed.

Immunoblot was performed with monocytes isolated of four different normal-weight donors and incubated with $10 \mu \mathrm{g} / \mathrm{ml}$ adiponectin for $24 \mathrm{~h}$, and annexin $A 6$ protein levels were found to be reduced (Figure 1B). Quantification of the immunoblots of 4 independent experiments revealed that annexin A6 protein expression was reduced to $79.0 \pm 10.2 \%$ by adiponectin $(P=0.012)$ whereas annexin $A 6$ mRNA was not altered (data not shown). A significant and similar reduction of annexin A6 was detected in monocytes of three different donors treated with $5.0,7.5$ or $10.0 \mu \mathrm{g} / \mathrm{ml}$ adiponectin whereas $2.5 \mu \mathrm{g} / \mathrm{ml}$ had no effect (Figure $1 \mathrm{C}$ ).

To determine the time-dependent reduction of annexin A6 levels, monocytes of 2 different donors were treated with or without $10 \mu \mathrm{g} / \mathrm{ml}$ adiponectin for $12 \mathrm{~h}, 18 \mathrm{~h}, 24 \mathrm{~h}$ or $30 \mathrm{~h}$. Whereas annexin $\mathrm{A6}$ in control treated cells was not altered, downregulation of annexin A6 was observed in the adiponectin treated cells after $24 \mathrm{~h}$ and $30 \mathrm{~h}$ (Figure 1D). Adiponectin activates the p38 MAPK (Tang et al., 2007; Weigert et al., 2008), and it was analysed whether downregulation of annexin A6 depends on this kinase. Annexin A6 protein expression was similar in the monocytes incubated with serum or serum and $100 \mathrm{nM}$ of the p38 MAPK inhibitor SB 203580 , respectively. Adiponectin reduced annexin A6 similarly in monocytes pretreated with the inhibitor and the respective controls (Figure 1E).

Adiponectin lowers cholesterylester storage in monocytic cells (Ouchi et al., 2001) but reduction of cellular cholesterol by lovastatin $(5 \mu \mathrm{M})$ or $\beta$-cyclodextrin $(1 \mathrm{mg} / \mathrm{ml})$ did not alter annexin $\mathrm{A} 6$ (Figure 1F). These findings are consistent with the observation that annexin A6 levels remained unchanged in cholesterol-, LDL-loaded (Grewal et al., 2000; Pons et al., 2001; de Diego et al., 2002; Cubells et al., 2007) or acetylated LDL-loaded THP1 cells (data not shown), indicating that intracellular cholesterol levels do not alter annexin A6 protein expression. Free fatty acids are elevated in obesity (Jensen, 1997), and therefore, the effect of palmitic acid and oleic acid on annexin A6 was also investigated. Increasing concentrations of 100,200 or $300 \mu \mathrm{M}$ of palmitic or oleic acid did not influence annexin $\mathrm{A} 6$ expression. (Figure $2 \mathrm{~A}$ ).

Adiponectin and fenofibrate activate PPAR $\alpha$ (Neumeier et al., 2006) but $0.5 \mu \mathrm{M}$ and $1 \mu \mathrm{M}$ fenofibrate did not reduce annexin $A 6$ levels (Figure 2B). Similarly, IL-6 (20 ng/ml) (Figure 2B) and IL-8 $(100,200$ and $300 \mathrm{ng} / \mathrm{ml}$, data not shown) that are both induced by adiponectin (Weigert et al., 2008) had no effect. Metformin and adiponectin stimulate the AMP-activated protein kinase (AMPK) (Towler et al., 2007) but incubation of monocytes of 3 different donors with $3 \mu \mathrm{M}, 6 \mu \mathrm{M}, 100 \mu \mathrm{M}$ and 500 $\mu \mathrm{M}$ metformin did not alter annexin $\mathrm{A} 6$ abundance (data not shown). In addition, the peroxisome proliferator-activated receptor $\gamma$ (PPAR $\gamma)$ agonist pioglitazone $(12.5 \mu \mathrm{M})$, lipopolysaccharide $(1 \mathrm{ng} / \mathrm{ml})$ (Figure 2B) and agonists of the retinoid $X$ receptor (RXR) and liver $X$ receptor (LXR), 9-cis-retinoic acid $(10 \mu \mathrm{M})$ and 25 -hydroxycholesterol $(10 \mu \mathrm{g} / \mathrm{ml})$ were tested but did not impact significantly on annexin A6 protein levels (data not shown).
A

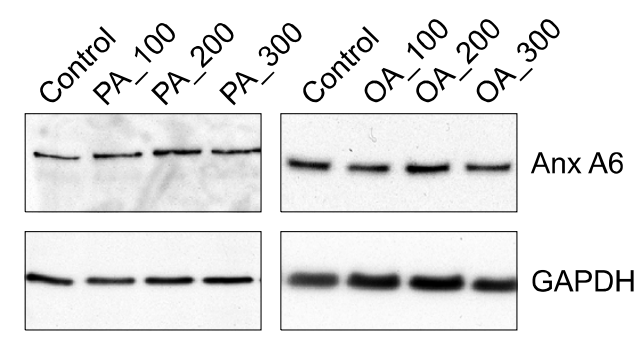

B

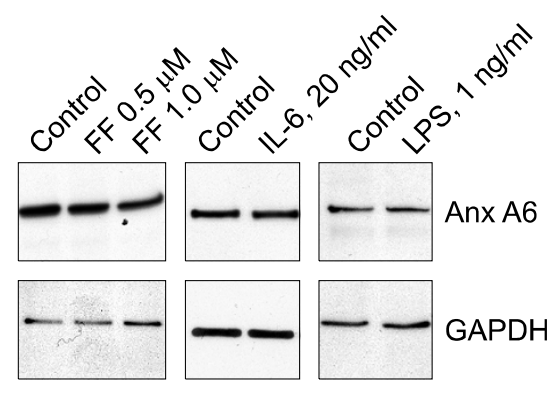

Figure 2. Fenofibrate, LPS, IL-6, and free fatty acid do not alter annexin A6 levels. (A) Annexin A6 (Anx A6) in monocytes incubated with 100,200 or $300 \mu \mathrm{M}$ palmitic or oleic acid for 24 h. (B) Annexin A6 (Anx A6) in monocytes incubated with fenofibrate (FF), IL-6 or LPS for $24 \mathrm{~h}$. 
A

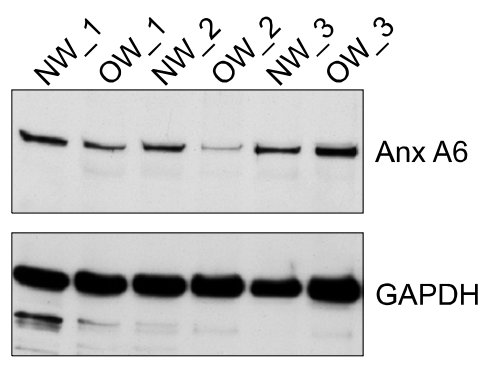

B

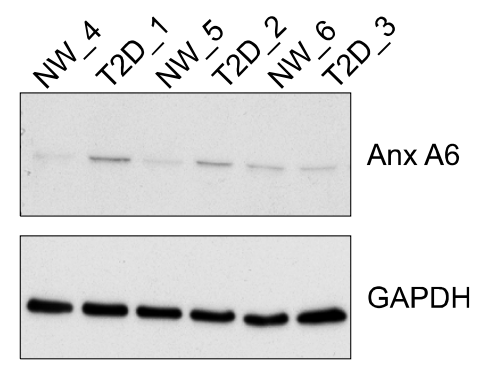

C

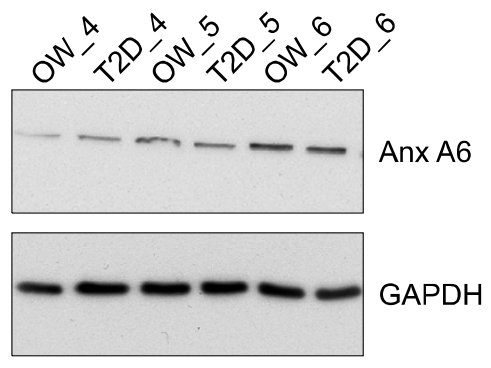

D

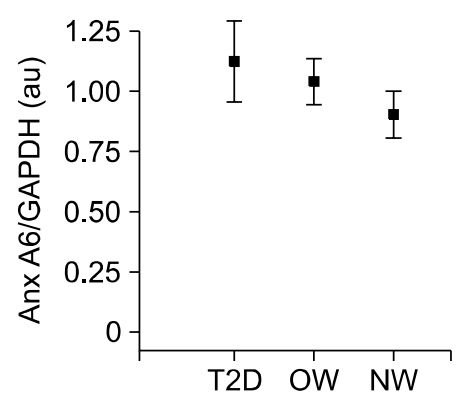

E

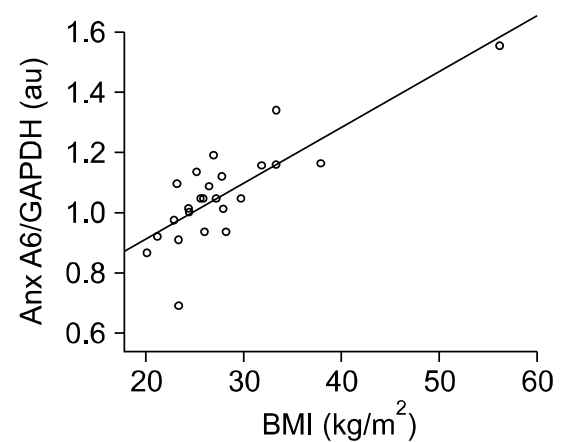

F

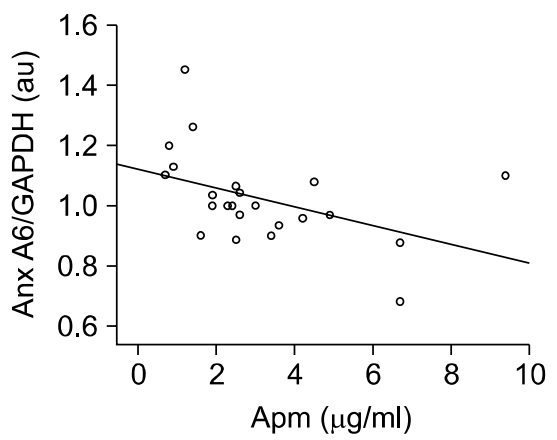

Figure 3. Annexin A6 in primary monocytes of normal-weight and overweight controls and T2D patients. (A) Annexin A6 (Anx A6) in monocytes isolated from the blood of overweight (OW_1 to OW_3) and normal weight controls (NW_1 to NW_3). (B) Annexin A6 (Anx A6) in monocytes isolated from the blood of type 2 diabetic patients (T2D_1 to T2D_3) and normal-weight controls (NW_4 to NW_6). (C) Annexin A6 (Anx A6) in monocytes isolated from the blood of type 2 diabetic patients (T2D_4 to T2D_6) and overweight controls (OW_4 to OW_6). (D) Quantification of the immunoblots partly shown in A, B and $C$. (E) Correlation of monocytic annexin A6 (Anx A6) levels with the body mass index (BMI) of the respective blood donors. (F) Correlation of monocytic annexin A6 (Anx A6) with serum adiponectin (Apm) of the respective blood donors.

To investigate whether the reduction of annexin A6 expression by adiponectin identified in vitro is also relevant in vivo, monocytes were isolated from the blood of probands with low systemic adiponectin. Quantification of immunoblots from monocytes of 8 type 2 diabetic patients (T2D), 7 overweight donors (OW) and 9 normal-weight controls (NW) (Figure $3 \mathrm{~A}$ to $\mathrm{C}$; Table 1 ) revealed that annexin A6 was $1.1 \pm 0.2$ in T2D monocytes, 1.0 \pm 0.1 in OW cells and $0.9 \pm 0.1$ in NW monocytes $(P=0.002$ compared to T2D and $P=0.005$ compared to $O W$ ) (Figure $3 D$ ). Thus annexin $A 6$ in primary monocytes of overweight probands and type 2 diabetics was significantly elevated when compared to monocytes of normal-weight controls. Monocytic annexin $A 6$ positively correlated with the BMI of the blood donors $(r=0.809, P<0.0001$, Figure $3 \mathrm{E})$ and negatively with their systemic adiponectin levels $(r=-0.442, P=0.035$, Figure $3 F)$. However, correlation of monocytic annexin A6 with adiponectin was lost after adjusting for BMI indicating that annexin A6 levels are not directly suppressed by adiponectin.

Table 1. Anthropometric and metabolic characteristics of the male study group.

\begin{tabular}{lcccl}
\hline & T2D & OW $($ WHR $>1)$ & NW $($ WHR $<1)$ & $P$-value \\
\hline Probands $(n)$ & $n=8$ & $n=7$ & $n=9$ & \\
Age (years) & $61.9 \pm 10.1$ & $63.8 \pm 10.3$ & $61.4 \pm 8.1$ & \\
BMl $\left(\mathrm{kg} / \mathrm{m}^{2}\right)$ & $32.5 \pm 10.6$ & $27.6 \pm 3.2$ & $23.8 \pm 2.5$ & $0.026^{\#}, 0.015^{\S}$ \\
WHR & $0.99 \pm 0.09$ & $1.04 \pm 0.03$ & $0.94 \pm 0.04$ & $0.002^{\#, \S}$ \\
Adiponectin $(\mu \mathrm{g} / \mathrm{ml})$ & $1.6 \pm 0.7$ & $3.7 \pm 2.8$ & $4.1 \pm 1.9$ & $0.002^{\S}$
\end{tabular}

\#OW versus NW, ${ }^{\S}$ T2D versus NW. BMI, body mass index; NW, normal-weight control group; OW, overweight control group; T2D; type 2 diabetes; WHR, waist to hip ratio. 


\section{Discussion}

In the current study it is demonstrated that adiponectin reduces annexin A6 expression in primary human monocytes. In accordance with this in-vitro finding elevated annexin A6 is detected in monocytes of T2D patients with low adiponectin. Monocytic annexin A6 levels strongly and positively correlate with the BMI of the blood donors indicating that overweight is associated with elevated monocytic annexin A6. Adiponectin is reduced in obesity and a modest negative correlation of monocytic annexin A6 with systemic adiponectin was identified but this association is lost after adjusting for BMI. This finding indicates that factors that are altered in obesity lead to increased annexin A6 in circulating monocytes and adiponectin has only a minor impact on monocytic annexin $\mathrm{A} 6$ in vivo. Annexin $A 6$ is even elevated in monocytes from healthy overweight probands although systemic adiponectin levels of these donors are comparable to those observed in the normal-weight blood donors.

Circulating IL-6 and IL-8 are increased in obesity but annexin A6 expression is not altered by IL-6 or IL-8 (Devaraj et al., 2000; Schober et al., 2007; Weigert et al., 2008). Free fatty acids and lipopolysaccharide are also elevated in overweight individuals (Jensen, 1997; Cani et al., 2008) but have no effect on annexin A6. Therefore, the mechanisms that lead to elevated annexin $A 6$ levels in obesity have yet to be identified.

Metformin and adiponectin activate the AMPK and thereby lower cellular cholesterol (Yamauchi et al., 2007; Misra, 2008). Neither metformin nor pharmaceutical reduction of cellular cholesterol reduce annexin $A 6$ indicating that stimulation of AMPK and lowering of cellular cholesterol levels do not alter annexin A6. Annexin A6 levels also remain unchanged in cholesterol-loaded monocytic cells (Grewal et al., 2000; Pons et al., 2001; de Diego et al., 2002; Cubells et al., 2007) further excluding that cellular cholesterol content regulates annexin A6. Beside AMPK, PPAR $\alpha$ is also activated by adiponectin (Yamauchi et al., 2007) but a PPARa antagonist (Neumeier et al., 2006) does not inhibit adiponectin mediated suppression of annexin A6 (own unpublished observation). Therefore, the adiponectin-stimulated pathways that downregulate annexin A6 levels have still to be identified in further studies.

PPAR $\alpha$ and PPAR $\gamma$ agonists like fenofibrate and pioglitazone, respectively, upregulate $A B C A 1$ and ABCG1 expression and thereby stimulate cholesterol efflux (Schmitz et al., 2005) but cellular annexin A6 is not affected by these drugs. There- fore, reduction of annexin $A 6$ seems to be regulated independent of $A B C A 1$ and $A B C G 1$ expression.

Overexpression of annexin $\mathrm{A} 6$ in $\mathrm{CHO}$ cells disturbs cholesterol efflux (Cubells et al., 2007) and elevated annexin A6 in monocytes may contribute to reduced cholesterol release that has been described in type 2 diabetic monocytes ( $\mathrm{Li}$ et al., 2008; Mauldin et al., 2008). Adiponectin stimulates cholesterol release in monocytic cells and besides induction of $\mathrm{ABC}$ transporters (Tsubakio-Yamamoto et al., 2008; Tian et al., 2009) the suppression of annexin A6 may reduce foam cell formation. Therefore, the current study provides new insights into the potential mechanisms of adiponectin which may impact the development of atherosclerotic diseases.

\section{Methods}

\section{Material}

Recombinant human adiponectin was from R\&D Systems (Wiesbaden-Nordenstadt, Germany), Vacutainer CPT was from Becton Dickinson (Franklin Lakes, NJ). GAPDH antibody was from New England Biolabs GmbH (Frankfurt, Germany). The annexin A6 antibody used in this study was recently described (Grewal et al., 2000; de Diego et al., 2002). The p38 MAPK inhibitor SB 203580, and lovastatin were from Calbiochem-Merck (Darmstadt, Germany). LightCycler FastStart DNA Master SYBR Green I was purchased from Roche (Mannheim, Germany). Metformin, AICAR, methyl- $\beta$-cyclodextrin, 9-cis-retinoic acid, 25-hydroxycholesterol, LPS (Escherichia coli serotype 055:B5), fenofibrate, pioglitazone, $\beta$-actin antibody, palmitic acid, and oleic acid were ordered from Sigma (Deisenhofen, Germany). Fatty acids were complexed to fatty acid-free bovine serum albumin (Roche) with a molar ratio of 1:1. Equal amounts of bovine serum albumin were added to control cells.

\section{Subjects}

The study protocol was approved by the local ethics committee and the investigation conforms with the principles outlined in the Declaration of Helsinki (1997). Each proband gave written informed consent. Monocytes were isolated from the blood of 8 male T2D patients, 7 male controls with a waist to hip ratio (WHR) above 1.0 (OW) and 9 male controls with a WHR below 1.0 (NW). Details of the study groups are given in Table 1 . Monocytes isolated of healthy blood donors were used for the in-vitro studies.

\section{Real-time RT-PCR}

Real-time RT-PCR was performed as described elsewhere (Weigert et al., 2008). Annexin A6 was amplified with AnxA6uni (5'-TGGCCTATCAGATGTGGGAAC-3') and AnxA6rev (5'-CTGCGTCAGGGTTGAAGTCAT-3'). 


\section{Isolation and culture of primary blood monocytes}

Peripheral blood leukocytes were isolated from $30 \mathrm{ml}$ of whole blood by Vacutainer CPT, and monocytes were further purified by magnetic separation with CD14 beads (Miltenyi Biotec, Bergisch Gladbach, Germany) (Stogbauer et al., 2008). Serum was coagulated with Thromborel S (Roche) and $\mathrm{CaCl}_{2}$ and was dialyzed 3-times against PBS for $2 \mathrm{~h}$ each. $3 \times 10^{6}$ monocytes were cultivated in $1 \mathrm{ml}$ RPMI supplemented with $10 \%$ autologous serum for $24 \mathrm{~h}$. Subsequently, the medium was replaced. Monocytes were either cultivated in RPMI supplemented with $10 \%$ autologous serum or in the identical medium supplemented with $10 \mu \mathrm{g} / \mathrm{ml}$ adiponectin. Supernatants were collected $24 \mathrm{~h}$ later and used for ELISA.

\section{Cell culture}

The generation of $\mathrm{CHO}$ cells overexpressing annexin $\mathrm{A} 6$ (CHOanx6) is described in detail elsewhere (Grewal et al., 2000). $\mathrm{CHO}$ cells (CHOwt) and $\mathrm{CHOanx6}$ cells were grown in Ham's F12, HeLa cells in DMEM, THP-1 and U937 cells in RPMI 1640 with $10 \%$ fetal calf serum (FCS), glutamine $(2 \mathrm{mM})$, penicillin $(100 \mathrm{U} / \mathrm{ml})$ and streptomycin $(100 \mu \mathrm{g} / \mathrm{ml})$ at $37^{\circ} \mathrm{C}$ and $5 \% \mathrm{CO}_{2}$. THP1 and U937 monocytes were differentiated into macrophages with PMA $(50 \mathrm{ng} / \mathrm{ml})$ for $72 \mathrm{~h}$.

\section{SDS-PAGE and immunoblotting}

$3 \times 10^{6}$ monocytes were washed with PBS and solubilized in $50 \mu \mathrm{l}$ RIPA buffer and $15 \mu \mathrm{g}$ of protein was used for immunoblot as recently described (Weigert et al., 2008). Quantification of the immunoblots was performed using OptiQuant software.

\section{Statistics}

Data are presented as the mean value \pm standard deviation (SPSS 15.0 for Windows). Statistical differences were analyzed by two-tailed Mann-Whitney $U$ Test or Students $t$-test for paired samples, and a value of $P<0.05$ was regarded as statistically significant. The Pearson's correlation was calculated using the SPSS 15.0 software.

\section{Acknowledgements}

The study was supported by a grant from the Deutsche Forschungsgemeinschaft (BU 1141/3-2) to CB. TG is supported by the National Health and Medical Reseach Council of Australia (510293, 510294) and the National Heart Foundation of Australia (G06S2559). CE is supported by the Ministerio de Educación y Ciencia (Spain, BMC2003-04754, GEN2003-20662, fellowship PR-20060142).

\section{References}

Arita Y, Kihara S, Ouchi N, Takahashi M, Maeda K, Miyagawa J, Hotta K, Shimomura I, Nakamura T, Miyaoka K, Kuriyama
H, Nishida M, Yamashita S, Okubo K, Matsubara K Muraguchi M, Ohmoto Y, Funahashi T, Matsuzawa Y. Paradoxical decrease of an adipose-specific protein, adiponectin, in obesity. Biochem Biophys Res Commun 1999;257:79-83

Bodzioch M, Orso E, Klucken J, Langmann T, Bottcher A, Diederich W, Drobnik W, Barlage S, Buchler C, PorschOzcurumez M, Kaminski WE, Hahmann HW, Oette K, Rothe G, Aslanidis C, Lackner KJ, Schmitz G. The gene encoding ATP-binding cassette transporter 1 is mutated in Tangier disease. Nat Genet 1999;22:347-51

Bonora E. The metabolic syndrome and cardiovascular disease. Ann Med 2006;38:64-80

Cani PD, Bibiloni R, Knauf C, Waget A, Neyrinck AM, Delzenne NM, Burcelin R. Changes in gut microbiota control metabolic endotoxemia-induced inflammation in high-fat diet-induced obesity and diabetes in mice. Diabetes 2008;57:1470-81

Cavelier C, Lorenzi I, Rohrer L, von Eckardstein A. Lipid efflux by the ATP-binding cassette transporters ABCA1 and ABCG1. Biochim Biophys Acta 2006;1761:655-66

Cubells L, Vila de Muga S, Tebar F, Wood P, Evans R, Ingelmo-Torres M, Calvo M, Gaus K, Pol A, Grewal T, Enrich C. Annexin A6-induced alterations in cholesterol transport and caveolin export from the Golgi complex. Traffic 2007; 8:1568-89

Cubells L, de Muga SV, Tebar F, Bonventre JV, Balsinde J, Pol A, Grewal T, Enrich C. Annexin A6-induced inhibition of cytoplasmic phospholipase A2 is linked to caveolin-1 export from the Golgi. J Biol Chem 2008;283:10174-83

de Diego I, Schwartz F, Siegfried H, Dauterstedt P, Heeren J, Beisiegel U, Enrich C, Grewal T. Cholesterol modulates the membrane binding and intracellular distribution of annexin 6 . J Biol Chem 2002;277:32187-94

Devaraj S, Jialal I. Alpha tocopherol supplementation decreases serum C-reactive protein and monocyte interleukin6 levels in normal volunteers and type 2 diabetic patients. Free Radic Biol Med 2000;29:790-2

Feig JE, Shamir R, Fisher EA. Atheroprotective effects of HDL: beyond reverse cholesterol transport. Curr Drug Targets 2008;9:196-203

Goldstein BJ, Scalia R. Adiponectin: A novel adipokine linking adipocytes and vascular function. $\mathrm{J}$ Clin Endocrinol Metab 2004;89:2563-8

Grewal T, Heeren J, Mewawala D, Schnitgerhans T, Wendt D, Salomon G, Enrich C, Beisiegel U, Jackle S. Annexin VI stimulates endocytosis and is involved in the trafficking of low density lipoprotein to the prelysosomal compartment. J Biol Chem 2000;275:33806-13

Hoyal CR, Thomas AP, Forman HJ. Hydroperoxide-induced increases in intracellular calcium due to annexin VI translocation and inactivation of plasma membrane Ca2+-ATPase. J Biol Chem 1996;271:29205-10

Jensen MD. Health consequences of fat distribution. Horm Res 1997;48 Suppl 5:88-92

Klucken J, Buchler C, Orso E, Kaminski WE, Porsch-Ozcurumez M, Liebisch G, Kapinsky M, Diederich W, Drobnik W, 
Dean M, Allikmets R, Schmitz G. ABCG1 (ABC8), the human homolog of the Drosophila white gene, is a regulator of macrophage cholesterol and phospholipid transport. Proc Natl Acad Sci U S A 2000;97:817-22

Mauldin JP, Nagelin MH, Wojcik AJ, Srinivasan S, Skaflen $\mathrm{MD}$, Ayers CR, McNamara CA, Hedrick CC. Reduced expression of ATP-binding cassette transporter G1 increases cholesterol accumulation in macrophages of patients with type 2 diabetes mellitus. Circulation 2008;117:2785-92

Misra P. AMP activated protein kinase: a next generation target for total metabolic control. Expert Opin Ther Targets 2008;12:91-100

Moss SE, Crumpton MJ. Alternative splicing gives rise to two forms of the p68 Ca2(+)-binding protein. FEBS Lett 1990; 261:299-302

Neumeier M, Weigert J, Schaffler A, Weiss TS, Schmidl C, Buttner R, Bollheimer C, Aslanidis C, Scholmerich J, Buechler C. Aldehyde oxidase 1 is highly abundant in hepatic steatosis and is downregulated by adiponectin and fenofibric acid in hepatocytes in vitro. Biochem Biophys Res Commun 2006;350:731-5

Ouchi N, Kihara S, Arita Y, Nishida M, Matsuyama A, Okamoto $\mathrm{Y}$, Ishigami M, Kuriyama H, Kishida K, Nishizawa $\mathrm{H}$, Hotta K, Muraguchi M, Ohmoto Y, Yamashita S, Funahashi T, Matsuzawa Y. Adipocyte-derived plasma protein, adiponectin, suppresses lipid accumulation and class A scavenger receptor expression in human monocyte-derived macrophages. Circulation 2001;103:1057-63

Pons M, Grewal T, Rius E, Schnitgerhans T, Jackle S, Enrich C. Evidence for the Involvement of annexin 6 in the trafficking between the endocytic compartment and lysosomes. Exp Cell Res 2001;269:13-22

Probst-Cousin S, Berghoff C, Neundorfer B, Heuss D. Annexin expression in inflammatory myopathies. Muscle Nerve 2004;30:102-10

Schmitz G, Langmann T. Transcriptional regulatory networks in lipid metabolism control ABCA1 expression. Biochim Biophys Acta 2005;1735:1-19

Schmitz G, Grandl M. Lipid homeostasis in macrophages implications for atherosclerosis. Rev Physiol Biochem Pharmacol 2008;160:93-125

Schober F, Neumeier M, Weigert J, Wurm S, Wanninger J,
Schaffler A, Dada A, Liebisch G, Schmitz G, Aslanidis C, Buechler C. Low molecular weight adiponectin negatively correlates with the waist circumference and monocytic IL-6 release. Biochem Biophys Res Commun 2007;361:968-73

Stogbauer F, Neumeier M, Weigert J, Wanninger J, Grandl M, Lehle K, Schmitz G, Aslanidis C, Schaffler A, Scholmerich $\mathrm{J}$, Buechler C. Highly efficient and low-cost method to isolate human blood monocytes with high purity. J Immunol Methods 2008;337:78-80

Tang CH, Chiu YC, Tan TW, Yang RS, Fu WM. Adiponectin enhances IL-6 production in human synovial fibroblast via an AdipoR1 receptor, AMPK, p38, and NF-kappa B pathway. J Immunol 2007;179:5483-92

Tian L, Luo N, Klein RL, Chung BH, Garvey WT, Fu Y. Adiponectin reduces lipid accumulation in macrophage foam cells. Atherosclerosis 2009;202:152-61

Towler MC, Hardie DG. AMP-activated protein kinase in metabolic control and insulin signaling. Circ Res 2007;100: 328-41

Tsubakio-Yamamoto K, Matsuura F, Koseki M, Oku H, Sandoval JC, Inagaki M, Nakatani K, Nakaoka H, Kawase R, Yuasa-Kawase M, Masuda D, Ohama T, Maeda N, Nakagawa-Toyama Y, Ishigami M, Nishida M, Kihara S, Shimomura I, Yamashita S. Adiponectin prevents atherosclerosis by increasing cholesterol efflux from macrophages. Biochem Biophys Res Commun 2008;375:390-4

Weigert J, Neumeier M, Wanninger J, Wurm S, Kopp A, Schober F, Filarsky M, Schaffler A, Zeitoun M, Aslanidis C Buechler $C$. Reduced response to adiponectin and lower abundance of adiponectin receptor proteins in type 2 diabetic monocytes. FEBS Lett 2008;582:1777-82

Yamauchi T, Nio Y, Maki T, Kobayashi M, Takazawa T, Iwabu M, Okada-Iwabu M, Kawamoto S, Kubota N, Kubota T, Ito Y, Kamon J, Tsuchida A, Kumagai K, Kozono H, Hada Y, Ogata H, Tokuyama K, Tsunoda M, Ide T, Murakami K, Awazawa M, Takamoto I, Froguel P, Hara K, Tobe K, Nagai R, Ueki K, Kadowaki T. Targeted disruption of AdipoR1 and AdipoR2 causes abrogation of adiponectin binding and metabolic actions. Nat Med 2007;13:332-9

Zhou H, Tan KC, Shiu SW, Wong Y. Determinants of leukocyte adenosine triphosphate-binding cassette transporter $\mathrm{G} 1$ gene expression in type 2 diabetes mellitus. Metabolism 2008;57:1135-40 